\title{
Perspectives of STEM Education from Physics Teachers' Points of View: A Quantitative Study
}

\author{
Ng Han Guan ${ }^{1}$, Muhammad Abd Hadi Bunyamin ${ }^{2, *}$, Noorzana Khamis² \\ ${ }^{1}$ Sekolah Menengah Kebangsaan Infant Jesus Convent Johor Bahru, Johor Bahru, Johor, Malaysia \\ ${ }^{2}$ School of Education, Faculty of Social Sciences and Humanities, Universiti Teknologi Malaysia, Johor Bahru, Johor, Malaysia
}

Received June 24, 2020; Revised October 1, 2020; Accepted November 7, 2020

\section{Cite This Paper in the following Citation Styles}

(a): [1] Ng Han Guan, Muhammad Abd Hadi Bunyamin, Noorzana Khamis , "Perspectives of STEM Education from Physics Teachers' Points of View: A Quantitative Study," Universal Journal of Educational Research, Vol. 8, No. 11C, pp. 72 - 82, 2020. DOI: 10.13189/ujer.2020.082309.

(b): Ng Han Guan, Muhammad Abd Hadi Bunyamin, Noorzana Khamis (2020). Perspectives of STEM Education from Physics Teachers' Points of View: A Quantitative Study. Universal Journal of Educational Research, 8(11C), 72 - 82. DOI: 10.13189/ujer.2020.082309.

Copyright $@ 2020$ by authors, all rights reserved. Authors agree that this article remains permanently open access under the terms of the Creative Commons Attribution License 4.0 International License

\begin{abstract}
Many perspectives of science, technology, engineering, and mathematics (STEM) are available, but which perspective is common among science teachers? This study aims to determine major and minor STEM education perspectives of physics teachers using Bybee's nine perspectives. A number of 70 in-service physics teachers were selected by using cluster random sampling. Data were collected via an online survey using questionnaire items derived from Bybee's review. Pilot testing, face validity assessment and content validity were conducted to determine 27 items that fitted with the nine perspectives of STEM education. Descriptive and inferential statistics were used to analyze the data. This study found that the major perspective of STEM held by the teachers is the perspective that deems engineering or technology as a bridge between science and mathematics. Many teachers were inclined to have inter/multi/transdisciplinary perspectives of STEM than single-disciplinary. Nonetheless, all seven perspectives that are inter/multi/transdisciplinary have no statistically significant differences among them. Additionally, two STEM perspectives that are single-disciplinary kinds have recorded a significant difference in their means. The implications of this study to the literature, STEM teaching and learning, and professional development programs are discussed.
\end{abstract}

Keywords Bybee, Perspectives of STEM Education, Physics Teachers, Quantitative Research

\section{Introduction}

Science, technology, engineering, and mathematics (STEM) education has become a primary focus of many countries because it is crucial for the economic advancement and for tackling complex problems of the world, such as climate change, by using multidisciplinary, interdisciplinary or transdisciplinary approaches. Many efforts have been made to reform STEM education toward those three approaches. In short, they are integrated STEM education approaches.

Yet, debates on various STEM perspectives are still happening (Czerniak \& Johnson, 2014). The literature has indicated that STEM has many kinds of integration such as integrating two or three STEM subjects or integrating all four STEM disciplines to become transdisciplinary (Bybee, 2013). Even the single-disciplinary STEM perspective still exists among educators (Breiner, Harkness, Johnson, \& Koehler, 2012). Different parties have conceptualized STEM in many different ways (Bunyamin et al., 2020; Nasri et al., 2020; Çalıșıcı \& Sümen, 2018; Türk et al., 2018). To date, this problem is expected to continue to happen because reaching an agreement on a common STEM perspective is quite challenging.

Nonetheless, one solution to this problem is to ask doers of STEM education, which are STEM teachers, about their perspectives on STEM education. As doers, they are the ones who will eventually execute STEM curriculum and teach in the classroom through teaching and learning. Their preference on certain STEM perspectives would influence 
their approach to STEM teaching where their thoughts, be it cognitive or affective, might control their teaching. If they have an integrated STEM perspective, they might teach STEM using that perspective.

Studies on STEM perspectives have produced mixed results. Some have found that many teachers or educators hold more of a type of integrated STEM perspective (Srikoom, Hanuscin, \& Faikhamta, 2017), but others have discovered a more single-disciplinary type (Breiner et al., 2012). The differences might be due to local factors that shape their perspectives on STEM such as efforts made by national governments or agencies in training teachers to teach integrated STEM (Srikoom et al., 2017; Curriculum Development Center, 2016).

Studying teachers' perspectives of STEM is still relevant to determine the major and minor perspectives possessed by them. The result could be used to inform STEM education stakeholders, especially national governments, school administrations, school teachers, and teacher educators to design STEM professional development programs that fit with teachers' thinking. An empirical study could show the recent perspectives of STEM possessed by many teachers so as to move toward an agreement on the major perspective of STEM among the doers of STEM education. Teachers' perspectives would allow all STEM education stakeholders to follow the most popular perspective of STEM to be adopted.

\section{Objective and Research Questions}

This study aimed to determine the current perspectives of STEM education among physics teachers. The research questions were: (1) what are the major and minor STEM education perspectives possessed by physics teachers? (2) is there any statistical difference among those perspectives?

The hypotheses were:

$\mathrm{H}_{0}$ : No significant difference in STEM perspectives among physics teachers.

$\mathrm{H}_{1}$ : A significant difference exists in STEM perspectives among physics teachers.

Physics teachers were selected because physics has emerged as a common subject included in many studies on STEM education (Kertil \& Gurel, 2016; Kim, Kim, Yuan, Hill, Doshi, \& Thai, 2015; Dare, Ellis, \& Roehrig, 2014). This is because physics is a subject that is most likely to be able to integrate other STEM subjects such as technology, engineering, and mathematics, in a lesson or unit (Bunyamin \& Finley, 2016).

\section{Literature Review}

Even today, debate on interdisciplinary science teaching is still happening. Czerniak and Johnson (2014) have mentioned that this debate has occurred because of the lack of consensus regarding the meaning of STEM integration. Bybee (2013) has outlined nine perspectives of STEM education: (1) STEM is science (or mathematics), (2) STEM is science and mathematics, (3) STEM is science and incorporates technology, engineering, or mathematics, (4) STEM as a quartet of separate disciplines, (5) STEM is science and mathematics connected by one technology or engineering program, (6) STEM means coordination across four disciplines, (7) STEM means mixing two or three disciplines, (8) STEM as complementary intersecting across disciplines, and (9) STEM means a transdisciplinary course or program. These nine perspectives by Bybee are used as this study's conceptual framework.

Bybee's comprehensive perspectives of STEM education are quite hierarchical. The first perspective seems to be totally single-disciplinary kind while the ninth perspective is a total integration of STEM disciplines. Nadelson and Seifert (2017) have proposed a STEM spectrum ranging from segregate/fragmented STEM to integrated. However, Nadelson and Seifert did not provide a comprehensive compilation of perspectives of STEM education unlike Bybee. The STEM spectrum, on the other hand, might be useful to determine the progress of integrated STEM education in K-12.

Due to the diverse STEM perspectives available, achieving a common perspective is needed to allow STEM teachers, administrators, and governments to go forward with a concerted effort in making a difference in STEM education. A consensus would allow all parties to work together and put aside their differences regarding multiple STEM perspectives.

Asking teachers, through research, might be the most logical way to get the consensus because they are the ones who will eventually teach STEM in classrooms. Their perspectives are central because their knowledge or beliefs might have a significant control on their teaching (Srikoom et al., 2017).

STEM and engineering design. Scholars have argued that engineering design could be a main integrator for STEM disciplines. Bryan, Moore, Johnson, and Roehrig (2016) have even included engineering design as one characteristic of integrated STEM teaching and learning. Next Generation Science Standards (NGSS, 2013) has also recommended teachers to adopt engineering practices for K-12. Engineering might be able to pull other STEM disciplines for integration.

Nonetheless, the recommendation of using engineering design activities or engineering practices needs confirmation among teachers whether they may favor them or not. Many initiatives done in integrated STEM education are currently connected to engineering design practices (Curriculum Development Center, 2016; Siew, Amir, \& Chong, 2015; Kelly \& Sung, 2017; McFadden \& Roehrig, 2019). Thus, determining teachers' preference on use of engineering design or practices is essential to 
confirm their preferences.

Use of engineering design is quite evident in one perspective of STEM education by Bybee (2013), which is "STEM is science and mathematics connected by one technology or engineering program.” In this regard, Bybee has deemed engineering or technology as a bridge between science and mathematics. This Bybee's perspective is similar to Bryan et al.'s (2016) definition of integrated STEM teaching and learning.

Studies on perspectives of STEM. To date, many studies done on STEM perspectives did not show a clear consensus. Ramli and Talib (2017) studied on Malaysian secondary school teachers' view on STEM. Only five science teachers were included as the research participants because they had adopted a qualitative approach by using interview method. The study had found that only three teachers were able to define STEM but they were unable to elaborate further on the meaning of STEM. Ramli and Talib's study could not be generalized to the whole population, in Malaysia, because they had used a qualitative design that is usually not intended to generate a conclusion for the whole population. Thus, the primary limitation was their research design.

Chalmers, Carter, Cooper, and Nason (2017) have done a review of literature on integrated STEM curriculum. Chalmers and colleagues have suggested the use of a continuum of integrations: within-discipline big ideas that have application in other STEM disciplines, cross-discipline big ideas, and encompassing big ideas. These three approaches are reflected in Bybee's nine perspectives of STEM education (Bybee, 2013). Chalmers et al.'s suggestions were pragmatic. They did not ask teachers to immediately adopt the ideal integration of STEM disciplines, rather acknowledge the integrations as a range from a simpler to a more complex integration. Yet, Chalmers and colleagues did not determine which type of integration that teachers favored because they did not conduct an empirical study. Determining teachers' major perspectives on STEM education would provide answers to this problem by conducting a study among teachers.

Kloser, Wilsey, Twohy, Immonen, and Navotas (2018) conducted a study on conceptions of STEM education in the United States. They used interviewing and drawing of STEM conceptual models as the methods. Sixty-four middle school teachers from nineteen schools were involved. Kloser et al. discovered that many teachers viewed science and mathematics as the most represented subjects for STEM. Technology had become an in-service subject while engineering was the most commonly missing subject. Kloser et al.'s study has hinted that teachers have given unequal representations of science, technology, engineering, and mathematics in STEM integration. This is logical because in typical school settings, science and mathematics are more established than technology and engineering. Yet, to move toward total integration of STEM, all subjects of STEM should be incorporated and are given equal representation. Kloser et al.'s study was conducted in 2018. Given that this is recent, it is assumed that ideal integration of STEM is still not really accepted even at the conceptual level.

Nonetheless, quite a different research finding was discovered in a recent study by Srikoom et al. (2017) in their research on in-service teachers' conceptions of STEM in Thailand. A questionnaire with an open-ended question was used to gather the data. A workshop on STEM education was conducted for teachers by the Institute for the Promotion of Teaching Science and Technology (IPST) and found that the majority of teachers (20\%) had viewed STEM education as transdisciplinary, which is the ninth perspective that Bybee (2013) proposed. The percentage was not really high, but the teachers who chose the transdisciplinary perspective of STEM had become the major group. The least was the teachers who chose the third perspective, STEM is science and incorporates technology, engineering, or mathematics, with $2.32 \%$.

It is expected that conducting studies on STEM perspectives across nations would produce different results by referring to Kloser et al.'s and Srikoom et al.'s studies, in the US and in Thailand. Both studies had used a similar type of research method which was qualitative design using interviewing and/or open-ended questionnaires. Nonetheless, both studies had produced different outcomes. The possible reason was the education settings. For this reason, the researchers wanted to carry out a study on STEM perspectives in a different nation, Malaysia, to determine the favored perspectives of STEM education among its teachers. The results will be compared with recent and past studies so that current progress of integrated STEM education could be determined and future action could be planned.

STEM and physics. Many studies done on integrated STEM education have shown that physics has emerged as the common subject included in STEM (Dare et al., 2014; Kertil \& Gurel, 2016; Kim et al., 2015; Siew et al., 2015). Physics is deemed a subject that could immediately apply engineering (Dare et al., 2014) because many topics covered in physics such as electricity and buoyancy could be applied to design products such as a prototype of functional circuit for animals' houses or submarine.

Compared to other subjects, such as mathematics is implicit in physics because many physics concepts such as force and motion involve making and interpreting graphs, which are mathematical aspects. For technology, robotics (Kim et al., 2015) has become a popular topic for design activities. By using physics as the platform for integration, all other STEM subjects could be involved.

It is reasonable to study physics teachers' perspectives of STEM, so that the thinking of the most likely teachers who could be able to integrate STEM disciplines would be revealed. Results of this study could inform physics teachers that they might be able to lead integrated STEM education in schools because of the nature of the physics subject. 


\section{Methodology}

\section{Research design}

This study was a descriptive nonexperimental survey because it could reflect a phenomenon within a population such as in this case, the physics teachers' perspectives on STEM education, in a particular time (Johnson \& Christensen, 2015; Moutinho \& Hutcheson, 2011). A cluster random sampling was used to determine a reasonable sample size that could represent the population of physics teachers in a district which is Johor Bahru, in Johor, Malaysia. This district was selected because it is the capital district of the state of Johor, the most diverse area, and is the district with the highest access to the state's initiatives of STEM education. The state education office is located in this district and so Johor Bahru is the most suitable district to study.

The researchers were given the total number of physics teachers in Johor Bahru which is 82 teachers, by the Education District Office. These teachers came from 42 national secondary schools in the district in the year 2019. On average, each school had two physics teachers. A sample size of 70 teachers should be acquired to represent the population, as the minimal size with 95\% confidence level (Krejcie \& Morgan, 1970). Thus, a minimal number of 35 schools should be included. However, all those 82 teachers from 42 schools were involved to maximize the size of sample as the size was considered small.

\section{Item construction and pilot study}

The researchers used the nine perspectives of STEM education by Bybee (2013) as the main framework because Bybee's descriptions were the most complete version of descriptions of STEM education compared to others. Nonetheless, Bybee did not elaborate STEM perspectives in the form of items, rather in the form of brief descriptions with diagrams. Therefore, the researchers adapted and adopted the descriptions by Bybee (2013) into comprehensible, simplified, and enriched items with several examples so that the respondents of the study could fully understand the items of the survey.

The items constructed were in the native language, Malay. The respondents received the research instrument in the native language version because they were mostly familiar with the language than English.

The researchers prepared a set of questionnaires consisting of two sections, Part A and Part B, with an estimated response time of 10-15 minutes. Part A was about demographic information regarding services while Section B was about perspectives on STEM education. The items in Section B used the five-level Likert scale: (1) strongly disagree; (2) disagree; (3) neutral; (4) agree; and (5) strongly agree (Johnson \& Christensen, 2010).

Initially, each of the nine perspectives of STEM (Bybee, 2013) had six items for the purpose of determining teachers' perspectives on STEM education for the pilot study. Thus, a total number of 54 items were constructed. This number was quite high and should be revised based on the pilot study's analysis of data to exclude irrelevant items. The greater the number of items per construct (STEM perspectives), the higher the probability of an item being replicated is (Little, Lindenberger, \& Nesselroade, 1999; Velicer \& Fava, 1998).

For the pilot study, the researchers had recruited 37 respondents from physics teachers from all over Malaysia to test the reliability of the research instrument and to refine it. They were given an online survey consisting of 54 items on STEM perspectives. Five out of 37 teachers were also selected for the think-aloud data collection method. They were asked to either verbally or in written forms state their thoughts and understanding of the items asked. Their responses were recorded and analyzed to refine the items used.

The final items selected were determined by the findings of the pilot study. The researchers used the Statistical Package for the Social Sciences (SPSS) software to obtain the Cronbach alpha values needed. Cronbach alpha value that was greater than 0.7 needed to be achieved for the purpose of reliability of the instrument's internal consistency (Johnson \& Christensen, 2010; Muijs, 2004). The pilot study's final result showed that all constructs of STEM perspectives achieved the reliability index of 0.7 . Each of the construct consisted of three items because they were the ones that contributed to the high values of reliability index, ranging from 0.721 to 0.901 . Three items were reasonable and were the minimal number to be used in a construct of measurement (Velicer \& Fava, 1998). With nine constructs, a total of 27 items were used for the actual study.

\section{Item validation}

All selected items based on the pilot study results had been well received by expert evaluators in the validity of the content. Two experts in the field of STEM education from local universities were appointed to assess the validity of the content of the research instrument. One of the nominees is a senior lecturer with more than ten years of STEM education experience. Meanwhile, another professor of 20 years of services in higher education is specializing in STEM and physics education. She currently works at a public university in Malaysia.

Views and suggestions by the evaluators, for some items, had no effect on the changes in those items. The items of the instrument were randomly arranged without following the structured constructs.

\section{Data collection}

The study was conducted via an online platform starting in early July 2019. A group of physics teachers who were teaching in Johor Bahru district was determined through an 
online group in a social media platform, Telegram. The main author was one of the members in the online group. The researchers had received high cooperation from all the physics teachers in the district. All 82 teachers were able to be contacted in the Telegram group with the help of the education district office. All of them had successfully answered the online survey within 9 days.

\section{Data analysis}

Normal distribution was identified before determining parametric or nonparametric analysis methods. The normalization of the data distribution was through skewness and kurtosis values analyzed by using the SPSS. The z-scores for the deviation and kurtosis values were used for the purpose of determining the validity of the data.

The mean, median, and mode values of each sub-construct (STEM perspectives) were calculated to test and answer the first research question. All mean, median, and mode values of each sub-construct were analyzed using the SPSS.

Subsequently, one-way analysis of variance (ANOVA) tests was used to determine whether there was a significant difference between the STEM perspectives (Johnson \& Christensen, 2010) to answer the second research question. The analysis was performed to determine the difference between the means and the p-value obtained. A p-value of 0.05 or less than 0.05 means that there was a significant difference between the nine STEM perspectives.

Post hoc tests were also conducted to analyze the differences between each of the nine STEM perspectives. Additionally, the effect size was also identified to determine the effect size for the comparisons made. According to Cohen (1988), the effect size, d, is small for $d$ $=0.2$, is medium for $\mathrm{d}=0.5$, and is large for $\mathrm{d}=0.8$.

\section{Sample size in actual study}

Initially, all 82 respondents had participated in the study. However, the results of the analysis have shown that 12 respondents were excluded from the analysis due to the low reliability of the findings. A total of 12 respondents answered all 27 items of the questionnaire with either agree or strongly agree on all items. Thus, the actual sample size analyzed for this study was only 70 but it still met the population representation requirements (Krejcie \& Morgan, 1970) for the Johor Bahru district physics teachers.

\section{Normality test of the actual study}

The normality of the data distribution is based on the value of skewness and kurtosis. The significance level (Alpha) for this small sample size study $(50<\mathrm{n}<300)$ was 0.05 and the z-score for the significance of deviation and kurtosis value was \pm 3.29 (Kim, 2013). The values of deviation and kurtosis were obtained using the SPSS, as shown in Table 1.

Table 1 shows that the values of deviation and kurtosis for all nine STEM perspectives, A to I, are within the range of \pm 3.29 . Besides, the $\mathrm{z}$-scores of deviation and kurtosis values for all nine STEM perspectives are shown in Table 2, where all $z$-scores are within the range of \pm 3.29 , so the study data distribution is normal.

Referring to Table 2, the lowest z-score of the skewness is on the perspective $\mathrm{F},-2.603$, while the highest is on the perspective $\mathrm{D}, 1.059$. For the $\mathrm{z}$-score of the kurtosis, the lowest is on perspective $\mathrm{E},-0.800$ while the highest is on perspective F, 1.814. Thus, all the z-scores of skewness and kurtosis for all perspectives of STEM were within the boundary of the proposed range of $-3.29<\mathrm{z}$-score $<3.29$ (Kim, 2013). Therefore, a parametric analysis method was adopted.

Table 1. Values of skewness and kurtosis of nine perspectives.

\begin{tabular}{|c|c|c|c|c|c|c|c|c|c|c|}
\hline \multicolumn{2}{|c|}{ Perspectives } & A & B & C & $\mathrm{D}$ & $\mathrm{E}$ & $\mathrm{F}$ & G & $\mathrm{H}$ & I \\
\hline \multirow{2}{*}{$\mathrm{N}$} & Valid & 70 & 70 & 70 & 70 & 70 & 70 & 70 & 70 & 70 \\
\hline & Missing & 0 & 0 & 0 & 0 & 0 & 0 & 0 & 0 & 0 \\
\hline \multicolumn{2}{|c|}{ Skewness } & .240 & -.521 & -.473 & .304 & .193 & -.747 & -.315 & -.480 & .016 \\
\hline \multicolumn{2}{|c|}{ Std. Error of Skewness } & .287 & .287 & .287 & .287 & .287 & .287 & .287 & .287 & .287 \\
\hline \multicolumn{2}{|c|}{ Kurtosis } & -.076 & .322 & -.223 & .272 & -.453 & 1.027 & -.073 & .498 & -.328 \\
\hline \multicolumn{2}{|c|}{ Std. Error of Kurtosis } & .566 & .566 & .566 & .566 & .566 & .566 & .566 & .566 & .566 \\
\hline
\end{tabular}

Table 2. Test of normality of univariate data by types of perspectives of STEM.

\begin{tabular}{ccccccc}
\hline \multirow{2}{*}{ Perspective } & \multicolumn{3}{c}{ Skewness } & \multicolumn{3}{c}{ Kurtosis } \\
& Statistic & Std. Error & z-score & Statistic & Std. Error & z-score \\
\hline A & 0.240 & 0.287 & 0.836 & -0.076 & 0.566 & -0.134 \\
B & -0.521 & 0.287 & -1.815 & 0.322 & 0.566 & 0.569 \\
C & -0.473 & 0.287 & -1.648 & -0.223 & 0.566 & -0.394 \\
D & 0.304 & 0.287 & 1.059 & 0.272 & 0.566 & 0.481 \\
E & 0.193 & 0.287 & 0.672 & -0.453 & 0.566 & -0.800 \\
F & -0.747 & 0.287 & -2.603 & 1.027 & 0.566 & 1.814 \\
G & -0.315 & 0.287 & -1.098 & -0.073 & 0.566 & -0.129 \\
H & -0.480 & 0.287 & -1.672 & 0.498 & 0.566 & 0.880 \\
I & 0.016 & 0.287 & 0.056 & -0.328 & 0.566 & -0.580 \\
\hline
\end{tabular}


Table 3. Mean, standard deviation, median and mode for nine STEM perspectives

\begin{tabular}{cccccccccc}
\hline \multirow{2}{*}{ Statistical value } & \multicolumn{10}{c}{ Perspectives } \\
\cline { 2 - 10 } & $\mathrm{A}$ & $\mathrm{B}$ & $\mathrm{C}$ & $\mathrm{D}$ & $\mathrm{E}$ & $\mathrm{F}$ & $\mathrm{G}$ & $\mathrm{H}$ & $\mathrm{I}$ \\
\hline Mean & 3.0429 & 3.9667 & 3.9381 & 2.5143 & 4.1524 & 4.1190 & 4.1143 & 4.1381 & 4.0857 \\
Std. Deviation & .78415 & .61424 & .72297 & .78571 & .48049 & .61394 & .63165 & .57172 & .53744 \\
Median & 3.0000 & 4.0000 & 4.0000 & 2.6667 & 4.0000 & 4.0000 & 4.0000 & 4.0000 & 4.0000 \\
Mode & 3.00 & 4.00 & 4.00 & 2.00 & 4.00 & 4.00 & 4.00 & 4.00 & 4.00 \\
\hline
\end{tabular}

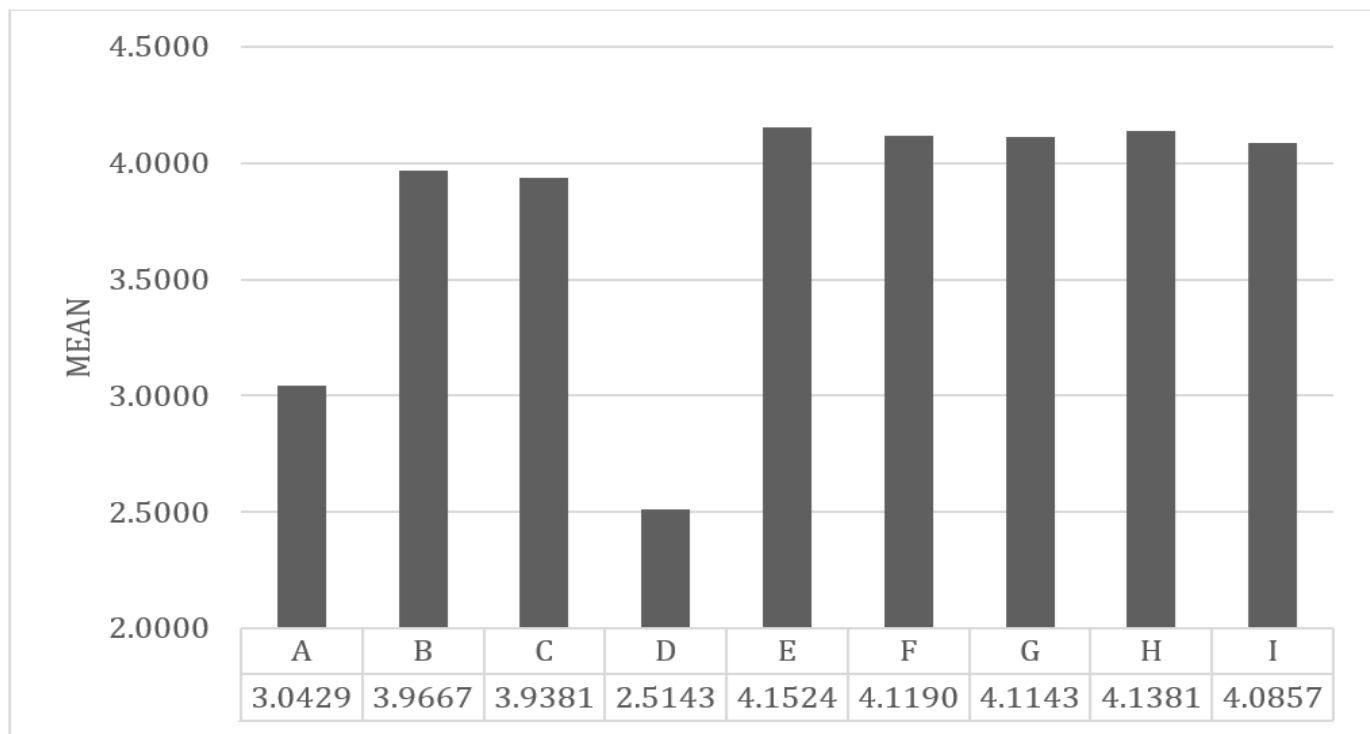

Figure 1. Comparison of mean scores between perspectives of STEM.

\section{Results}

\section{Descriptive analysis}

To answer the first research question, the researchers analyzed the mean values obtained by each STEM perspective construct. The STEM perspective with the highest mean value is considered to be major while the lowest is the minor. Table 3 shows the results of the mean value analysis along with standard deviation, median and modes.

Based on Table 3, standard deviations of all perspectives are less than 1.00 and are within the small standard deviation range (Johnson \& Christensen, 2010).

Perspective $\mathrm{E}$ has emerged as the major STEM perspective with the mean value of 4.1524 , followed by perspective $\mathrm{H}$ with mean of 4.1381, and perspective $\mathrm{F}$ with mean of 4.1190. Perspective D has become the minor STEM perspective with the lowest mean value, 2.5143, followed by perspective A, 3.0429, and perspective C, 3.9381. Additionally, perspective D gives a 2.00 mode value where most physics teachers chose the scale of 2.00 and most of them also chose the scale of 3.00 for perspective A.

Of the seven other STEM perspectives other than perspectives $\mathrm{A}$ and $\mathrm{D}$, most physics teachers chose a 4.00 scale (mode value), which is a high level of agreement for most of these STEM perspectives. Furthermore, based on
Figure 1, the mean value gap between all nine STEM perspective constructs shows that perspectives $\mathrm{A}$ and $\mathrm{D}$ have very large gaps with perspectives B, C, E, F, G, H and I. In fact, perspectives $\mathrm{A}$ and $\mathrm{D}$ both have shown a quite large gap in their mean values.

Thus, in general, based on the illustration shown in Figure 1, it is shown that perspectives $\mathrm{A}$ and $\mathrm{D}$ have given the highest gap compared to perspectives B, C, E, F, G, H and I. These large gaps have signified a possible statistical difference between the mean values. Thus, an inference analysis was performed to complete the descriptive analysis.

\section{Inferential analysis}

One-way ANOVA tests were performed to test the hypotheses. Table 4 shows the results of one-way ANOVA to compare mean scores between STEM perspectives.

Table 4. One-way ANOVA test results for comparison of mean scores of nine perspectives

\begin{tabular}{ccccccc}
\hline & $\begin{array}{c}\text { Sum of } \\
\text { squares }\end{array}$ & df & $\begin{array}{c}\text { Mean } \\
\text { square }\end{array}$ & F & Sig. & $\begin{array}{c}\text { Partial eta } \\
\text { squared }\end{array}$ \\
\hline Contrast & 195.474 & 8 & 24.434 & 58.535 & .000 & .430 \\
Error & 259.225 & 621 & .417 & & & \\
\hline
\end{tabular}

Note. The F tests the effect of Construct. This test is based on the linearly independent pairwise comparisons among the estimated marginal means.

One-way ANOVA test results have shown that the $\mathrm{F}$ 
value $(\mathrm{df}=8,621)=58,535, \mathrm{p}<.05$ is significant with an effect size of 0.430 . The null hypothesis is rejected and the results of the one-way ANOVA test have revealed that there are significant differences between the nine constructs of STEM perspectives. This result (partial $\eta 2=0.430$ ) has recorded a medium effect size (Cohen, 1988).

To strengthen the results from the ANOVA test, a Post Hoc Multiple Comparisons test was conducted to determine mean differences across constructs of STEM perspectives. Table 5 shows the results.

Based on Table 5, four observations could be made. First, perspective A has recorded significant mean differences with all other STEM perspectives without any exceptions. All recorded probability values for all eight (8) pairs of perspective A compared to perspective B to I are $\mathrm{p}=0.000$. Thus, there are significant differences between perspective A and all other perspectives of STEM.
Second, perspective D shows significant mean differences with all other STEM perspectives without any exceptions, like the situation of perspective A. All recorded probability values for all perspective $D$ pairs are $p=0.000$. The similarity found between perspectives $\mathrm{D}$ and $\mathrm{A}$ has indicated that there might be a similar characteristic between these two perspectives.

Third, there is even a significant mean difference between perspectives $A$ and $D$ with a p-value of 0.000 . To mention, these two perspectives, even though might share a similar characteristic (first and second observations mentioned), they might also have a different nature.

Fourth, each seven perspectives of STEM education, B, C, E, F, G, H and I, has produced a p-value of greater than 0.05 among them. This means no significant differences exist between them. This result has indicated that all seven perspectives might share a similar characteristic.

Table 5. Post hoc multiple comparisons examination of nine STEM perspectives

\begin{tabular}{|c|c|c|c|c|c|c|}
\hline \multirow{2}{*}{ Construct (i) } & \multirow{2}{*}{ Construct (j) } & \multirow{2}{*}{$\begin{array}{l}\text { Mean difference } \\
\text { (i-j) }\end{array}$} & \multirow{2}{*}{ Std. error } & \multirow{2}{*}{ Sig. } & \multicolumn{2}{|c|}{ 95\% Confidence interval } \\
\hline & & & & & Lower bound & Upper bound \\
\hline \multirow{8}{*}{ Perspective A } & Perspective B & $-.9233^{*}$ & .10921 & .000 & -1.2632 & -.5833 \\
\hline & Perspective C & $-.8951^{*}$ & .10921 & .000 & -1.2351 & -.5552 \\
\hline & Perspective D & $.5289^{*}$ & .10921 & .000 & .1889 & .8688 \\
\hline & Perspective E & $-1.1099^{*}$ & .10921 & .000 & -1.4498 & -.7699 \\
\hline & Perspective F & $-1.0763^{*}$ & .10921 & .000 & -1.4162 & -.7363 \\
\hline & Perspective G & $-1.0714^{*}$ & .10921 & .000 & -1.4114 & -.7315 \\
\hline & Perspective $\mathrm{H}$ & $-1.0949^{*}$ & .10921 & .000 & -1.4348 & -.7549 \\
\hline & Perspective I & $-1.0427^{*}$ & .10921 & .000 & -1.3827 & -.7028 \\
\hline \multirow{8}{*}{ Perspective B } & Perspective A & $.9233^{*}$ & .10921 & .000 & .5833 & 1.2632 \\
\hline & Perspective C & .0281 & .10921 & 1.000 & -.3118 & .3681 \\
\hline & Perspective D & $1.4521^{*}$ & .10921 & .000 & 1.1122 & 1.7921 \\
\hline & Perspective E & -.1866 & .10921 & .741 & -.5265 & .1534 \\
\hline & Perspective F & -.1530 & .10921 & .897 & -.4929 & .1869 \\
\hline & Perspective G & -.1481 & .10921 & .913 & -.4881 & .1918 \\
\hline & Perspective H & -.1716 & .10921 & .820 & -.5115 & .1684 \\
\hline & Perspective I & -.1194 & .10921 & .975 & -.4594 & .2205 \\
\hline \multirow{8}{*}{ Perspective C } & Perspective A & $.8951^{*}$ & .10921 & .000 & .5552 & 1.2351 \\
\hline & Perspective B & -.0281 & .10921 & 1.000 & -.3681 & .3118 \\
\hline & Perspective D & $1.4240^{*}$ & .10921 & .000 & 1.0841 & 1.7639 \\
\hline & Perspective E & -.2147 & .10921 & .568 & -.5547 & .1252 \\
\hline & Perspective F & -.1811 & .10921 & .771 & -.5211 & .1588 \\
\hline & Perspective G & -.1763 & .10921 & .797 & -.5162 & .1637 \\
\hline & Perspective $\mathrm{H}$ & -.1997 & .10921 & .663 & -.5397 & .1402 \\
\hline & Perspective I & -.1476 & .10921 & .915 & -.4875 & .1924 \\
\hline \multirow{8}{*}{ Perspective D } & Perspective A & $-.5289^{*}$ & .10921 & .000 & -.8688 & -.1889 \\
\hline & Perspective B & $-1.4521^{*}$ & .10921 & .000 & -1.7921 & -1.1122 \\
\hline & Perspective C & $-1.4240^{*}$ & .10921 & .000 & -1.7639 & -1.0841 \\
\hline & Perspective E & $-1.6387^{*}$ & .10921 & .000 & -1.9787 & -1.2988 \\
\hline & Perspective F & $-1.6051^{*}$ & .10921 & .000 & -1.9451 & -1.2652 \\
\hline & Perspective G & $-1.6003^{*}$ & .10921 & .000 & -1.9402 & -1.2603 \\
\hline & Perspective H & $-1.6237^{*}$ & .10921 & .000 & -1.9637 & -1.2838 \\
\hline & Perspective I & $-1.5716^{*}$ & .10921 & .000 & -1.9115 & -1.2316 \\
\hline
\end{tabular}


Table 5 Continued

\begin{tabular}{|c|c|c|c|c|c|c|}
\hline \multirow{8}{*}{ Perspective E } & Perspective A & $1.1099^{*}$ & .10921 & .000 & .7699 & 1.4498 \\
\hline & Perspective B & .1866 & .10921 & .741 & -.1534 & .5265 \\
\hline & Perspective C & .2147 & .10921 & .568 & -.1252 & .5547 \\
\hline & Perspective D & $1.6387^{*}$ & .10921 & .000 & 1.2988 & 1.9787 \\
\hline & Perspective F & .0336 & .10921 & 1.000 & -.3064 & .3735 \\
\hline & Perspective G & .0384 & .10921 & 1.000 & -.3015 & .3784 \\
\hline & Perspective H & .0150 & .10921 & 1.000 & -.3249 & .3549 \\
\hline & Perspective I & .0671 & .10921 & 1.000 & -.2728 & .4071 \\
\hline \multirow{8}{*}{ Perspective F } & Perspective A & $1.0763^{*}$ & .10921 & .000 & .7363 & 1.4162 \\
\hline & Perspective B & .1530 & .10921 & .897 & -.1869 & .4929 \\
\hline & Perspective C & .1811 & .10921 & .771 & -.1588 & .5211 \\
\hline & Perspective D & $1.6051^{*}$ & .10921 & .000 & 1.2652 & 1.9451 \\
\hline & Perspective E & -.0336 & .10921 & 1.000 & -.3735 & .3064 \\
\hline & Perspective G & .0049 & .10921 & 1.000 & -.3351 & .3448 \\
\hline & Perspective H & -.0186 & .10921 & 1.000 & -.3585 & .3214 \\
\hline & Perspective I & .0336 & .10921 & 1.000 & -.3064 & .3735 \\
\hline \multirow{8}{*}{ Perspective G } & Perspective A & $1.0714^{*}$ & .10921 & .000 & .7315 & 1.4114 \\
\hline & Perspective B & .1481 & .10921 & .913 & -.1918 & .4881 \\
\hline & Perspective C & .1763 & .10921 & .797 & -.1637 & .5162 \\
\hline & Perspective D & $1.6003^{*}$ & .10921 & .000 & 1.2603 & 1.9402 \\
\hline & Perspective E & -.0384 & .10921 & 1.000 & -.3784 & .3015 \\
\hline & Perspective F & -.0049 & .10921 & 1.000 & -.3448 & .3351 \\
\hline & Perspective H & -.0234 & .10921 & 1.000 & -.3634 & .3165 \\
\hline & Perspective I & .0287 & .10921 & 1.000 & -.3112 & .3687 \\
\hline \multirow{8}{*}{ Perspective H } & Perspective A & $1.0949^{*}$ & .10921 & .000 & .7549 & 1.4348 \\
\hline & Perspective B & .1716 & .10921 & .820 & -.1684 & .5115 \\
\hline & Perspective C & .1997 & .10921 & .663 & -.1402 & .5397 \\
\hline & Perspective D & $1.6237^{*}$ & .10921 & .000 & 1.2838 & 1.9637 \\
\hline & Perspective E & -.0150 & .10921 & 1.000 & -.3549 & .3249 \\
\hline & Perspective F & .0186 & .10921 & 1.000 & -.3214 & .3585 \\
\hline & Perspective G & .0234 & .10921 & 1.000 & -.3165 & .3634 \\
\hline & Perspective I & .0521 & .10921 & 1.000 & -.2878 & .3921 \\
\hline \multirow{8}{*}{ Perspective I } & Perspective A & $1.0427^{*}$ & .10921 & .000 & .7028 & 1.3827 \\
\hline & Perspective B & .1194 & .10921 & .975 & -.2205 & .4594 \\
\hline & Perspective C & .1476 & .10921 & .915 & -.1924 & .4875 \\
\hline & Perspective D & $1.5716^{*}$ & .10921 & .000 & 1.2316 & 1.9115 \\
\hline & Perspective E & -.0671 & .10921 & 1.000 & -.4071 & .2728 \\
\hline & Perspective F & -.0336 & .10921 & 1.000 & -.3735 & .3064 \\
\hline & Perspective G & -.0287 & .10921 & 1.000 & -.3687 & .3112 \\
\hline & Perspective H & -.0521 & .10921 & 1.000 & -.3921 & .2878 \\
\hline
\end{tabular}

Notes. Based on observed means. The error term is Mean Square (Error) $=.417$. The mean difference is significant at the .05 level. 


\section{Discussion}

STEM education perspectives studied were: (1) perspective A: STEM is science (or mathematics), (2) perspective B: STEM is science and mathematics, (3) perspective C: STEM is science and incorporates technology, engineering, or mathematics, (4) perspective D: STEM as a quartet of separate disciplines, (5) perspective E: STEM is science and mathematics connected by one technology or engineering program, (6) perspective F: STEM means coordination across four disciplines, (7) perspective G: STEM means mixing two or three disciplines, (8) perspective $\mathrm{H}$ : STEM as complementary intersecting across disciplines, and (9) perspective I: STEM means a transdisciplinary course or program (Bybee, 2013).

Key findings regarding the study on perspectives of STEM education are discussed to produce insights for new literature contributions and practical contributions to integrated STEM teaching and learning. Limitations and future studies are discussed as well.

\section{Perspective $E$ and engineering design}

The most favored perspective of STEM education by many physics teachers in this study is perspective $\mathrm{E}$, which is "STEM is science and mathematics connected by one technology or engineering program." The perspective is reflected in many teaching and learning activities done in schools nowadays through engineering design activities (Kelly \& Sung, 2017; McFadden \& Roehrig, 2019). Around the globe, including the United States, use of engineering practices in K-12 is recommended (NGSS, 2013, Curriculum Development Center, 2016).

Scholars have even believed that STEM integration needs to include engineering design activities (Bryan et al., 2016). Engineering design has now become a major integrator for STEM, especially in integrating science and mathematics. This finding regarding the major preference of the physics teachers on perspective $\mathrm{E}$ is in-line with the current progress of integrated STEM education worldwide. Even though this study was done at the local level, in Johor Bahru, Malaysia, the finding is consistent with the world's recent progress in integrated STEM education. Engineering design that can integrate science and mathematics is one useful platform that could be capitalized further for STEM integration. Teachers may use engineering design activities as a start for integration of two or more STEM disciplines, especially science and mathematics, which is consistent with the perspective $\mathrm{E}$ that many teachers in this study have favored.

\section{Single disciplinary versus multi/inter/transdisciplinary STEM}

Perspectives A and D, which are single-disciplinary types of STEM perspectives, both have been found to have significant differences with all other perspectives, which are multi/inter/transdisciplinary perspectives, B, C, E, F, G, $\mathrm{H}$, and $\mathrm{I}$. The perspectives that are multi/inter/transdisciplinary have got clear higher mean values than the single disciplinary ones.

Perspectives A and D both are traditional-type of STEM education because they either protect/recognize each discipline of STEM separately or simply recognize STEM as science per se. Significantly lower values of mean for these two perspectives, $\mathrm{A}$ and $\mathrm{D}$, compared to those that are multi/inter/transdisciplinary perspectives of STEM indicate that the physics teachers have started to consider in their mind on integration of STEM rather than single-disciplinary. This finding is different from the past study by Breiner et al. (2012) where they found that single-disciplinary or segregated STEM was dominant, while recent studies (Kloser et al., 2018; Srikoom et al., 2017) have indicated either a fair acceptance to integrated STEM education.

The perceived change in the physics teachers' mind on STEM perspectives, especially in thinking of integration across STEM disciplines than segregated STEM disciplines might be a starting point for them to accept integrated STEM approaches. This also implies that many efforts done to transform STEM education toward integration have started to show initial success, especially after the release of the NGSS in 2013 and of the new curriculum of science in many countries that includes integrated STEM education approaches (e.g. Curriculum Development Center, 2016).

The progress of integrated STEM education could now be deemed "half-way" by referring to the STEM spectrum suggested by Nadelson and Seifert (2017). The next step is to ensure that teachers will keep learning how to integrate STEM fully, by training them to adopt and adapt the transdisciplinary STEM perspective.

Governments and professional development providers need to be alert that many teachers will need training to integrate STEM because they have started to make a "buy-in" on STEM integration. Sustaining their thinking on STEM integration is critical to ensure they will be able to adapt and adopt STEM integration in actual practice of teaching.

\section{Two versions of single-disciplinary STEM}

Perspectives A and D both have shown a statistically significant difference, too. Even though they both are single disciplinary perspectives of STEM, perspective A is more toward STEM as science per se while perspective D seems to acknowledge other disciplines, technology, engineering or mathematics as STEM. Perspective A has got a higher mean value than perspective $\mathrm{D}$. The physics teachers have favored perspective A than $\mathrm{D}$. The difference in mean has indicated that these two perspectives should be treated as different in nature and has suggested that single disciplinary STEM has two types. Bybee (2013) is true when differentiating perspectives A and D. This study has 
empirically supported the Bybee's work.

Scholars may learn that STEM exclusively for science versus STEM for science or technology or engineering or mathematics are different. The first would make STEM more specialized for science while the second makes STEM inclusive in nature, covering any four disciplines of STEM. Many teachers in this study have chosen perspective A than $\mathrm{D}$, which means they are inclined to see STEM as science. This is logical because they are teachers who teach a science subject, physics.

Probably, if this study is expanded to engineering or technology teachers, the result might be different where they might not choose perspective A, rather, perspective D because it includes engineering and technology. Different respondents would likely produce different results due to their respective academic qualifications. Future studies can do research on this matter to confirm this assumption.

\section{Acknowledging multi/inter/transdisciplinary STEM perspectives}

Seven perspectives of STEM, perspectives B, C, E, H, F, $\mathrm{G}$, and I, have produced a similar result which is no statistical difference in the mean values between them. These seven perspectives are all multi/inter/transdisciplinary STEM. No differences in mean values might suggest that they all could be seen as "alike". The reason is that all these seven perspectives have a similarity which is integrations that include more than one discipline in STEM, though the levels of integrations are varied.

This finding is quite different from the Bybee's framework (Bybee, 2013) that has differentiated those seven perspectives. Nonetheless, it is important to note that this study does not intend to dismiss Bybee's comprehensive perspectives of STEM education, rather the researchers think as a teacher, a practitioner, that has choices in taking an appropriate perspective of STEM that suits with his/her needs. In actual teaching, a teacher may adopt a perspective of STEM that fits with a particular context. For instance, he/she, today, may adopt perspective $E$ that uses engineering to connect science and mathematics. While, on the next day of teaching, she/he may adopt perspective $\mathrm{C}$ that uses science and incorporates technology, engineering or mathematics in teaching a topic. Many teachers are believed pragmatic because as practitioners, they teach according to appropriateness of time, resources, and materials. Even different teachers have different contexts (Nadelson \& Seifert, 2017) because they are different in experience, knowledge, and skills.

Teachers who are already capable of using a complex kind of integration, such as in perspective I, "STEM means a transdisciplinary course or program" might be able to immediately adapt and adopt the perspective for their teaching. However, teachers who are less capable in integrating could start with a simpler integration such as in perspective E, "STEM is science and mathematics connected by one technology or engineering program."

Giving teachers support and sufficient time would allow them to learn to teach integrated STEM based on their own pace. This is actually an acknowledgement of diversity in STEM integration perspectives to recognize multiple types of integration. Letting teachers to move freely from one integration type to another could make them less pressured to transform their STEM teaching and make them teach according to their respective conditions. This would create a comfortable and supportive environment for integrated STEM teaching and learning. From time to time, they would be able to move from a simpler integration to a complex one so that they will be able to reach the transdisciplinary STEM.

\section{Limitations and future studies}

This study includes physics teachers and does not include teachers in other STEM disciplines. Inclusion of teachers from all STEM disciplines might give different results and thus provide different insights regarding teachers' thought on certain perspectives of STEM. Future studies can do similar research to other teachers in other STEM disciplines, technology, engineering, and/or mathematics.

The survey was the only method used for data collection. Using other methods such as interviewing could enrich the quantitative findings and provide deeper insights regarding reasons for preferring certain perspectives of STEM. Future studies may use qualitative approaches to strengthen quantitative data.

\section{REFERENCES}

[1] Bunyamin, M. A. H., Talib, C. A., Ahmad, N. J., Ibrahim, N. H., \& Surif, J. (2020). Current Teaching Practice of Physics Teachers and Implications for Integrated STEM Education. Universal Journal of Educational Research, 8(5A), 18-28.

[2] Bunyamin, M. A. H. \& Finley, F. (2016, January 7-9). [Paper presentation]. International Conference of the Association for Science Teacher Education, Reno, NV, the United States.

[3] Breiner, J. M., Harkness, S. S., Johnson, C. C., \& Koehler, C. M. (2012). What is STEM? A discussion about conceptions of STEM in education and partnerships. School Science and Mathematics, 112(1), 3-11. https://doi.org/10.1111/j.19498594.2011.00109.x

[4] Bryan, L., Moore, T., Johnson, C., \& Roehrig, G. (2016). Integrated STEM education. In C. Johnson, E. Peters-Burton, \& T. Moore (Eds.), STEM road map: A framework for integrated STEM education (pp. 23-37). Routledge.

[5] Bybee, R. (2013). The case for STEM education: Challenges and opportunities. NSTA Press. 
[6] Çalıșıc1, H., \& Sümen, Ö.-Ö. (2018). Metaphorical Perceptions of Prospective Teachers for STEM Education. Universal Journal of Educational Research, 6(5), 871-880.

[7] Chalmers, C., Carter, M. L., Cooper, T., \& Nason, R. (2017). Implementing "big ideas" to advance the teaching and learning of science, technology, engineering, and mathematics (STEM). International Journal of Science and Mathematics Education, 15(1), 25-43. https://doi.org/10.10 07/s10763-017-9799-1

[8] Cohen, J. (1988). Statistical power analysis for the behavioral sciences (2nd ed.). Lawrence Erlbaum Associates.

[9] Curriculum Development Center. (2016). Implementation guide for Science, Technology, Engineering, and Mathematics (STEM) in teaching and learning. Ministry of Education of Malaysia.

[10] Czerniak, C. M., \& Johnson, C. C. (2014). Interdisciplinary science teaching. In N. G. Lederman, \& S. K. Abell (Eds.), Handbook of research on science education (pp. 395-411). Routledge.

[11] Dare, E. A., Ellis, J. A., \& Roehrig, G. H. (2014). Driven by beliefs: Understanding challenges physical science teachers face when integrating engineering and physics when integrating engineering and physics. Journal of Pre-College Engineering Education Research, 4(2), Article 5. https://doi.org/10.7771/2157-9288.1098

[12] Johnson, B., \& Christensen, L. (2015). Educational research: Quantitative, qualitative, and mixed approaches (5th ed.). SAGE Publications.

[13] Johnson, B., \& Christensen, L. (2010). Educational research: Quantitative, qualitative, and mixed approaches (4th ed.). SAGE Publications.

[14] Kelley, T., \& Sung, E. (2017). Examining elementary school students' transfer of learning through engineering design using think-aloud protocol analysis. Journal of Technology Education, 28(2), 83-108.https://doi.org/10.21061/jte.v28i2 .a.5

[15] Kertil, M., \& Gurel, C. (2016). Mathematical modeling: A bridge to STEM education. International Journal of Education in Mathematics, Science and Technology, 4(1), 44. https://doi.org/10.46328/ijemst.v4i1.77

[16] Kim, C., Kim, D., Yuan, J., Hill, R. B., Doshi, P., \& Thai, C. N. (2015). Robotics to promote elementary education pre-service teachers' STEM engagement, learning, and teaching. Computers and Education, 91, 14-31. https://doi.org/10.1016/j.compedu.2015.08.005

[17] Kloser, M., Wilsey, M., Twohy, K. E., Immonen, A. D., \& Navotas, A. C. (2018). "We do STEM": Unsettled conceptions of STEM education in middle school STEM classrooms. School Science and Mathematics, 118(8), 335-347. https://doi.org/10.1111/ssm.12304

[18] Krejcie, R. V., \& Morgan, D. W. (1970). Determining sample size for research activities. Educational and Psychological Measurement, 30(3), 607-610. https://doi.or g/10.1177/001316447003000308

[19] Little, T. D., Lindenberger, U., \& Nesselroade, J. R. (1999). On selecting indicators for multivariate measurement and modelling with latent variables: When "good" indicators are bad and" bad" indicators are good. Psychological Methods, 4(2), 192-211. https://doi.org/10.1037/1082-989X.4.2.192

[20] McFadden, J., \& Roehrig, G. (2019). Engineering design in the elementary science classroom: Supporting student discourse during an engineering design challenge. International Journal of Technology and Design Education, 29(2), 231-262. https://doi.org/10.1007/s10798-018-9444-5

[21] Moutinho, L., \& Hutcheson, G. D. (2011). The sage dictionary of quantitative management research. SAGE Publications.

[22] Muijs, D. (2004). Doing quantitative research in education with SPSS. SAGE Publications.

[23] Nadelson, L. S., \& Seifert, A. L. (2017). Integrated STEM defined: Contexts, challenges, and the future. The Journal of Educational Research, 110(3), 221-223.https://doi.org/10.1 080/00220671.2017.1289775

[24] Nasri, N. M., Nasri, N., \& Talib, M. A. A. (2020). Toward Developing Malaysia STEM Teacher Standard: Early Framework. Universal Journal of Educational Research, 8(7), 3077-3084.

[25] National Research Council. (2012). A framework for K-12 science education: Practices, crosscutting concepts, and core ideas. National Academies Press.

[26] Ramli, N. F., \& Talib, O. (2017). Can education institution implement STEM? From Malaysian teachers' view. International Journal of Academic Research in Business and Social Sciences, 7(3), 721-732. http://dx.doi.org/10.6007/IJ ARBSS/v7-i3/2772

[27] Siew, N. M., Amir, N., \& Chong, C. L. (2015). The perceptions of pre-service and in-service teachers regarding a project-based STEM approach to teaching science. SpringerPlus, 4(1), Article 8. https://doi.org/10.1186/21931801-4-8

[28] Srikoom, W., Hanuscin, D. L., \& Faikhamta, C. (2017). Perceptions of in-service teachers toward teaching STEM in Thailand. Asia-Pacific Forum on Science Learning and Teaching, 18(2), 1-23. https://www.eduhk.hk/apfslt/v18_is sue2/srikoom/index.htm

[29] Türk, N., Kalayc1, N., \& Yamak, H. (2018). New Trends in Higher Education in the Globalizing World: STEM in Teacher Education. Universal Journal of Educational Research, 6(6), 1286-1304.

[30] Velicer, W. F., \& Fava, J. L. (1998). Affects of variable and subject sampling on factor pattern recovery. Psychological Methods, 3(2), 231-251. https://doi.org/10.1037/1082-989X .3.2.231 